\title{
Household air pollution as an important factor in the complex relationship between altitude and COPD
}

\author{
Xavier Basagaña $a^{1,2,3}$ \\ Affiliations: ${ }^{1}$ ISGlobal, Barcelona, Spain. ${ }^{2}$ Universitat Pompeu Fabra (UPF), Barcelona, Spain. ${ }^{3}$ CIBER \\ Epidemiología y Salud Pública (CIBERESP), Madrid, Spain.
}

Correspondence: Xavier Basagaña, Dr. Aiguader 88, 08003 Barcelona, Spain.

E-mail: xavier.basaganađisglobal.org

@ERSpublications

Household air pollution, whose relationship with COPD is still understudied, is yet another factor explaining the complex relationship between altitude and COPD http://ow.ly/Ao4K30nmxDt

Cite this article as: Basagaña X. Household air pollution as an important factor in the complex relationship between altitude and COPD. Eur Respir J 2019; 53: 1802454 [https://doi.org/10.1183/ 13993003.02454-2018].

The relationship between altitude and chronic obstructive pulmonary disease (COPD) remains controversial. Altitude per se is a relevant variable for respiratory health, as subjects living at high altitude are exposed to lower atmospheric pressure, which by affecting the driving pressure for gas exchange in the lungs leads to hypoxia [1]. It has been reported that high altitude natives have larger lungs and higher forced vital capacity (FVC) than predicted, potentially as an adaptation mechanism, which is relevant for COPD research, as it consequently leads to lower forced expiratory volume in $1 \mathrm{~s}$ to FVC ratios [2-4].

Apart from that, though, altitude is indirectly related to many other variables that in turn can affect respiratory health in general and COPD in particular. These include exposure to colder temperatures and lower humidity, absence of house dust mite allergens above $1600 \mathrm{~m} \mathrm{[5],} \mathrm{malnutrition} \mathrm{[6],} \mathrm{low} \mathrm{birth} \mathrm{weight}$ [7], genetic variations [8] or living in a more rural environment, which may lead to differences in occupation and occupational exposures or physical activity levels, among other factors (figure 1). In this issue of the European Respiratory Journal (ERJ), BRAKEMA et al. [9] analyse the effect of another variable, household air pollution, which they hypothesise can explain the differences in COPD prevalence by altitude.

Indeed, especially in low and middle income settings, high altitude is associated with an increased exposure to household air pollution, as colder temperatures lead to increased use of solid fuel-based heating (e.g. biomass burning) and to lower household ventilation. In addition, altitude also influences the type of biomass used, as wood is often replaced by dung at altitudes above the tree line [10]. Different fuels can lead to different emissions that in turn may have different toxicity [11]. In many settings, the indoor levels of pollution can reach high levels. The level of air pollution is often measured by the concentration of particles of less than $2.5 \mu \mathrm{m}$ in the air (PM2.5). The average PM2.5 levels measured by BRAKEMA et al. [9] in the highlands of Kyrgyzstan were $290 \mu \mathrm{g} \cdot \mathrm{m}^{-3}$, and the maximum levels reached $5822 \mu \mathrm{g} \cdot \mathrm{m}^{-3}$. This contrasts with the World Health Organization recommended 24-h level of $25 \mu \mathrm{g} \cdot \mathrm{m}^{-3}$. To put that in perspective, the legal annual value in the European Union (EU) of $25 \mu \mathrm{g} \cdot \mathrm{m}^{-3}$ was only exceeded in $5 \%$ of the monitoring stations in the EU, with a maximum annual concentration of around $63 \mu \mathrm{g} \cdot \mathrm{m}^{-3}$ [12]. Yet, many studies in Europe and the USA, with much lower air pollution levels, have 


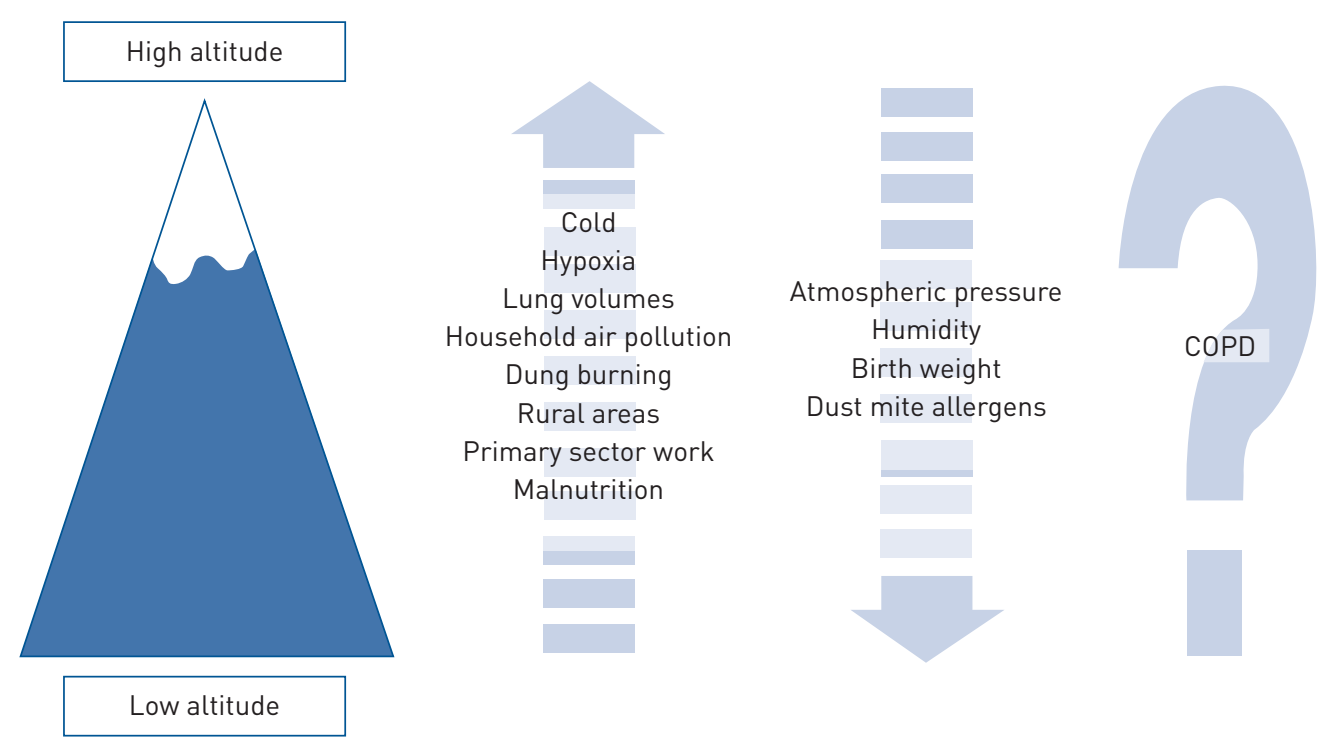

FIGURE 1 Selection of factors that have been associated with altitude. COPD: chronic obstructive pulmonary disease.

reported associations between ambient air pollution and respiratory health. For example, recent papers in the ERJ report that higher air pollution exposure may lead to increased airway obstruction in adolescence [13] and to increased risk of subclinical interstitial lung disease [14]. The ERJ also published recently a joint European Respiratory Society (ERS)/American Thoracic Society (ATS) policy statement that summarises the evidence on the adverse health effects of air pollution, not only in the respiratory system but also on other organ systems [15]. In terms of COPD, the report highlights that, although it is well established that high levels of air pollution contribute to exacerbations, the evidence that exposure to air pollution causes COPD is still considered insufficient. Note that those findings refer to the effect of outdoor, rather than indoor, air pollution.

The respiratory health effects of household (i.e. indoor) air pollution are reviewed in another ERS/ATS report recently published in the ERJ [16]. The report nicely summarises the problem, the global burden of disease associated with household air pollution exposure, the available evidence with regards to respiratory health and the biological mechanisms involved. In addition, it also discusses the future needs in terms of research and of effective interventions. For COPD, the report highlights that most of the available research has been conducted for smoking-related COPD, and little has been done on household air pollution-related COPD. However, in low income countries, smoking accounts for only half of the COPD cases and household air pollution is a key factor, especially in women. Thus, more research is needed to understand COPD related to household air pollution, which may have a different course than smoking-related COPD. Some of the available evidence suggests differences between smoking- and household air pollution-related COPD in terms of chronic bronchitis symptoms, bronchial hyperresponsiveness, airflow obstruction, diffusion capacity, small airway disease, emphysema or rate of decline in lung function [16].

The number of people exposed to household air pollution worldwide is three times higher than those actively smoking, which shows the relevance of this topic [16]. Some rather coarse estimates compare the inhaled dose of particles of those cooking in settings with high household air pollution with smoking one cigarette per day [16]. Although this dose is much smaller than that of a heavy smoker, one must consider that exposure to household air pollution starts prenatally and is sustained during childhood, adolescence and adulthood. This is important if one considers that COPD pathogenesis may begin early in life, as recently discussed in the Controversies in COPD series in the ERJ [17]. Early exposure to air pollution affects airway function and lung growth, which can lead to reduced maximum attained adult lung function that, in turn, may interact with accelerated decline in lung function and lead to early onset COPD [15, 17].

The study reported by BRAKEMA et al. [9] is a welcome addition to the still limited literature on household air pollution and health in low and middle income settings [16]. Studies on the effects of long term exposure to air pollution are especially needed, as the current estimates of global burden of disease at high pollution levels are based on cohort studies in high income countries (with low levels) and extrapolations based on exposure to passive and active smoking [18]. One of the difficulties of conducting air pollution studies in low income settings is obtaining accurate measurements of air pollution exposure. BRAKEMA et al. [9] 
objectively measured air pollution exposure by using personal monitors, which provide improvements over previous studies that used self-reported exposure. Still, monitoring was done for less than $5 \mathrm{~h}$ on a single day for each subject. The high cost associated with using expensive equipment on a large number of participants is a common limitation in epidemiological studies. In resource-poor settings, as described by BRAKEMA et al. [9], this is further complicated by restricted access to electricity to charge the batteries of the equipment. Other approaches based on modelling to predict individual air pollution exposure, often used in epidemiological studies in high income countries, are also more challenging in settings with high household air pollution exposure [19].

Household air pollution has a very important impact on respiratory health in low income countries. Thus, it is plausible that household air pollution explains part of the reported effects of altitude. Indeed, in the study reported by BRAKEMA et al. [9], household air pollution showed an effect on COPD prevalence, although altitude still remained as a significant predictor. Epidemiological studies on air pollution are always threatened by residual confounding, as those with higher exposure are often different in terms of other variables, especially those linked to socioeconomic status. When we include altitude in the equation, the picture becomes even more complex, as highlanders differ from lowlanders in a large number of factors relevant for respiratory health.

Despite its limitations, the study reported by BRAKEMA et al. [9] represents a step forward on the highly relevant topic of air pollution health effects in low and middle income countries with high exposure. Larger studies incorporating further advances in exposure assessment are expected in the near future to cover the many existing gaps in the scientific literature.

Acknowledgement: I thank Otavio Ranzani (ISGlobal) for critical reading of the text. ISGlobal is a member of the CERCA Programme, Generalitat de Catalunya.

Conflict of interest: None declared.

\section{References}

Peacock AJ. ABC of oxygen: oxygen at high altitude. BMJ 1998; 317: 1063-1066.

Wu T, Kayser B. High altitude adaptation in Tibetans. High Alt Med Biol 2006; 7: 193-208.

Brody JS, Lahiri S, Simpser M, et al. Lung elasticity and airway dynamics in Peruvian natives to high altitude. J Appl Physiol Respir Environ Exerc Physiol 1977; 42: 245-251.

4 Vinnikov D, Blanc PD, Brimkulov N. Spirometry reference values for a Kyrgyz population. Clin Respir J 2018; 12 : 826-828.

5 Rijssenbeek-Nouwens LH, Fieten KB, Bron AO, et al. High-altitude treatment in atopic and nonatopic patients with severe asthma. Eur Respir J 2012; 40: 1374-1380.

6 Morales R, Aguilar AM, Calzadilla A. Geography and culture matter for malnutrition in Bolivia. Econ Hum Biol 2004; 2: 373-389.

7 Jensen GM, Moore LG. The effect of high altitude and other risk factors on birthweight: independent or interactive effects? Am J Public Health 1997; 87: 1003-1007.

8 Moore LG. Human genetic adaptation to high altitude. High Alt Med Biol 2001; 2: 257-279.

9 Brakema EA, Tabyshova A, Kasteleyn MJ, et al. High COPD prevalence at high altitude: does household air pollution play a role? Eur Respir J 2019; 53: 1801193.

10 Yucra S, Tapia V, Steenland K, et al. Maternal exposure to biomass smoke and carbon monoxide in relation to adverse pregnancy outcome in two high altitude cities of Peru. Environ Res 2014; 130: 29-33.

11 Šyc M, Horák J, Hopan F, et al. Effect of fuels and domestic heating appliance types on emission factors of selected organic pollutants. Environ Sci Technol 2011; 45: 9427-9434.

12 Guerreiro C, González Ortiz A, de Leeuw F, et al. Air Quality in Europe - 2018 report. Luxembourg, Publications Office of the European Environment Agency, 2018. Available from: www.eea.europa.eu/publications/air-quality-ineurope-2018

13 Milanzi EB, Koppelman GH, Smit HA, et al. Air pollution exposure and lung function until age 16 years: the PIAMA birth cohort study. Eur Respir J 2018; 52: 1800218.

14 Sack C, Vedal S, Sheppard L, et al. Air pollution and subclinical interstitial lung disease: the Multi-Ethnic Study of Atherosclerosis (MESA) air-lung study. Eur Respir J 2017; 50: 1700559.

15 Thurston GD, Kipen H, Annesi-Maesano I, et al. A joint ERS/ATS policy statement: what constitutes an adverse health effect of air pollution? An analytical framework. Eur Respir J 2017; 49: 1600419.

16 Sood A, Assad NA, Barnes PJ, et al. ERS/ATS workshop report on respiratory health effects of household air pollution. Eur Respir J 2018; 51: 1700698.

17 Soriano JB, Polverino F, Cosio BG. What is early COPD and why is it important? Eur Respir J 2018; 52: 1801448.

18 Tonne C. A call for epidemiology where the air pollution is. Lancet Planet Health 2017; 1: e355-e356.

19 Milà C, Salmon M, Sanchez M, et al. When, where, and what? Characterizing personal PM2.5 exposure in periurban India by integrating GPS, wearable camera, and ambient and personal monitoring data. Environ Sci Technol 2018; 52: 13481-13490. 